\title{
Efficacy of Immunodiagnosis of Falciparum Malaria at Different Levels of Parasitemia
}

\author{
Mejbah Uddin Ahmed ${ }^{1}$, Mohammad Akram Hossain², Abul Hossain Khan ${ }^{3}$, \\ Salah Uddin Ahmed ${ }^{4}$
}

\begin{abstract}
Background: Among the several human species of malarial parasites, Plasmodium falciparum can cause severe infection and if left untreated, there may be fatal complications. Early diagnosis and prompt treatment have been proposed to reduce the morbidity and mortality from malaria. Objective: To assess the diagnostic efficacy of antigen detection by immunochromatographic test (ICT) at different levels of parasitemia for diagnosis of malaria. Materials and Methods: This study was carried out in the department of Microbiology, Mymensingh Medical College for a period of one year from July 2005 to June 2006. A total of 98 clinically suspected malaria patients were included in this study. Peripheral blood films (PBF) were examined under microscope and parasite count/ $\mu$ L of blood was performed. Subsequently ICT for malaria antigen was done for each case. Results: Out of 59 cases positive by microscopic examination of blood films, 54 cases had parasitemia $>600$ parasites/ $\mu L$ of blood and all these cases were positive by ICT for malaria antigen. Rest 5 cases showed parasitemia $\leqslant 600$ parasites/ $\mu L$ of blood and one case was found positive by ICT for malaria antigen. Conclusion: Immunochromatographic test can be used for early diagnosis of malaria with hyperparasitemia, especially for cerebral malaria.
\end{abstract}

Keywords: Immunodiagnosis, Severe malaria, Hyperparasitemia

J Enam Med Col 2013; 3(2): 88-90

\section{Introduction}

Malaria is a febrile illness caused by four human species of the genus plasmodium, which causes more deaths worldwide than any other parasitic disease. Among the four human species Plasmodium falciparum is the most dangerous and is responsible for severe malaria. ${ }^{1}$

Malaria is a major public health problem in Bangladesh. Thirteen, out of 64 districts are seriously affected by malaria and among the malaria cases, more than $70 \%$ are falciparum malaria. The emergence and spread of antimalarial drug resistant falciparum malaria is worsening the malaria problem in Bangladesh. ${ }^{2,3}$
Malaria may result in a wide variety of symptoms; ranging from no symptoms or very mild symptoms to severe disease and even death. ${ }^{4}$ If falciparum malaria is not treated properly, complicated 'severe malaria' may occur. According to WHO 'severe malaria' may be defined by at least one of the following criteria: absence of detectable, nonmalarious causes of severe anemia, prostration, respiratory distress, convulsion, impaired consciousness, hypoglycemia, hemoglobinuria, circulatory collapse, renal failure, pulmonary edema and combined with the presence of $P$. falciparum 'hyperparasitemia'. The term 'hyperparasitemia' is

\footnotetext{
1. Associate Professor, Department of Microbiology, Enam Medical College, Savar, Dhaka

2. Professor, Department of Microbiology, Mymensingh Medical College, Mymensingh

3. Department of Microbiology, Khwaja Younus Ali Medical College, Enayetpur, Sirajgonj

4. Graded specialist, Department of ENT, Combined Military Hospital, Dhaka Cantonment, Dhaka

Correspondence Mejbah Uddin Ahmed,Email: mejbahua@gmail.com
} 
defined as a parasite density $>5 \%$ parasitemia or $>250,000$ parasites $/ \mu \mathrm{L}$ of blood. Among the complications of severe malaria, cerebral malaria is the most common. The case fatality rate with severe malaria may exceed $20 \%$ or more. ${ }^{1,3,5} \mathrm{~A}$ prompt and accurate diagnosis is the key to reduce the sufferings and complications.

Malaria is usually diagnosed clinically and by microscopic examination of peripheral blood film. Clinical diagnosis may overlap with other febrile illnesses. Therefore, diagnosis based on clinical grounds should be confirmed by laboratory investigations. In addition to traditional blood film microscopy, fluorescence microscopy, detection of antigen and antibody by ICT, enzyme-linked immunosorbent assay (ELISA) and molecular techniques are also available. Among all the methods, microscopic examination of blood film is regarded as the 'gold standard'.6,7 This method is relatively simple and cost-effective. But it is time consuming, needs expert microscopist and sensitivity is questionable at low level of parasitemia. ${ }^{8}$ Moreover, in infection with $P$. falciparum, parasites are sequestered in the deep capillaries of spleen, liver and bone marrow and parasite detection may be missed in the blood films due to insufficient number of parasites. ${ }^{9}$ For these reasons, in case of severe malaria, especially 'cerebral malaria' where parasitemia remains high $(>2,500$ parasites $/ \mu \mathrm{L})$, antigen detection by ICT may be an alternative choice. Because, this is a rapid test and is able to detect low level of parasitemia $(60-100$ parasites $/ \mu \mathrm{L}$ of blood) ${ }^{6}$

In addition to conventional microscopy for diagnosis of malaria, a rapid and reliable test like ICT for antigen can contribute to reduce the mortality and morbidity. Therefore, this study was designed to see the efficacy of ICT for detection of antigen at different levels of parasitemia.

\section{Materials and Methods}

This study was carried out in the department of Microbiology, Mymensingh Medical College during the period of July 2005 to June 2006. A total of 98 clinically suspected malaria cases were selected from Haluaghat Thana Health Complex, Mymensingh, Mymensingh Medical
College Hospital and Community Based Medical College Hospital, Mymensingh. Cases were selected clinically on the basis of fever with chill and rigor, sweating, splenomegaly, hepatomegaly, headache, vomiting, fatigue and abdominal discomfort. Relevant history, clinical findings and results of laboratory investigations of every case was systematically recorded in a predesigned data sheet and subsequently analyzed by computer program SPSS version 12.0.

Capillary blood from the tip of the finger for thick and thin films and intravenous blood for ICT were collected aseptically. The slides of thick and thin films were labeled and stained with Giemsa stain. ${ }^{5}$ Parasites were detected and counted and subsequently antigen was detected by ICT method for each case.

\section{Results}

Out of 98 clinically suspected cases 59 (60.20\%) were positive by microscopic examination of peripheral blood film and among them $55(56.12 \%)$ were positive by ICT for antigen (Table I).

Table I: Rate of detection of malaria by microscopy and ICT methods

$\begin{array}{lcc}\text { Tests } & \text { Positive } & \text { Negative } \\ \text { Peripheral blood film }(\mathrm{n}=98) & 59(60.20 \%) & 39(39.80 \%) \\ \text { ICT for antigen }(\mathrm{n}=98) & 55(56.12 \%) & 43(43.88 \%)\end{array}$

Table II shows the distribution of parasitemia and their relation with ICT for antigen. Parasitemia between 10,00049,999 parasites $/ \mu \mathrm{L}$ of blood was found in 20 cases. Seventeen cases showed parasitemia $\mu \mathrm{L}$

of blood. The cases with parasitemia $>600$ parasites $/ \mu \mathrm{L}$ of blood were positive by ICT for antigen. Parasitemia parasites $/ \mu \mathrm{L}$ of blood were found in $5(8.7 \%)$ cases of which $1(20 \%)$ was positive by ICT for antigen.

Table II: Distribution of parasitemia among the 59 microscopy positive cases and their relation with ICT for antigen

$\begin{array}{lcc}\begin{array}{l}\text { Parasite count/ } \\ \mu \mathrm{L} \text { of blood }\end{array} & \text { Number }(\%) & \text { Positive by ICT for antigen (\%) } \\ >50000 & 17(28.81) & 17(100) \\ 10000-49999 & 20(33) & 20(100) \\ 1000-9999 & 13(22) & 13(100) \\ 601-999 & 04(6.77) & 04(100) \\ \leqslant 600 & 05(8.47) & 01(20) \\ \text { Total } & 59 & 55\end{array}$




\section{Discussion}

In the present study, out of 98 clinically suspected malaria cases, $59(60.20 \%)$ were positive for malarial parasite by microscopic examination of peripheral blood film and $57(58.16 \%)$ were positive by ICT for antigen. Khan et al in Pakistan found $45.5 \%$ cases positive by microscopic examination of peripheral blood film and $43.2 \%$ positive by ICT for antigen. ${ }^{10}$ In our study, parasitemia between $10,000-49,999 / \mu \mathrm{L}$ of blood was found in highest number of cases $(20,33 \%)$ and $17(28.81 \%)$ cases with 50,000 parasites $/ \mu \mathrm{L}$ of blood. In a study in Thailand, Pattanasin et al reported highest number of patients $(37,26.24 \%)$ had parasitemia between $5,000-50,000 / \mu \mathrm{L}$ of blood and $20(14.18 \%)$ patients had parasitemia $>50,000 / \mu \mathrm{L}$ of blood. ${ }^{11}$ We found all $54(100 \%)$ cases with parasitemia $>600 / \mu 1$ of blood positive by ICT for antigen. Cooke et al from Gambia in 1999 found $100 \%$ cases positive by ICT for antigen with parasitemia $>500 / \mu \mathrm{L}$ of blood. ${ }^{12} \mathrm{We}$ found one case positive by ICT for antigen when parasite count was $<600$ parasites $/ \mu \mathrm{L}$ of blood. In a study in Kuwait, Iqbal et al found $96 \%$ sensitivity when parasitemia was $>500$ parasites $/ \mu \mathrm{L}$ and $44 \%$ sensitivity when parasitemia was $<500$ parasites $/ \mu \mathrm{L}^{7}$ Kakkilaya in 2003 observed that many studies showed $>95 \%$ sensitivity when parasitemia was 500 parasites $/ \mu \mathrm{L} .{ }^{13}$ From the above discussion it is observed that some results are consistent with our findings and some remarkably differ from the present study. These variations of results may be because of different places and use of different diagnostic kits.

In conclusion, diagnosis of malaria by ICT is simple, easy to perform, can be done as bedside test and diagnostic efficacy of ICT is satisfactory. So, this method can be used in case of malaria, especially for cerebral malaria where urgent diagnosis is needed.

\section{References}

1. Trampuz A, Jereb M, Muzlovic I, Rajesh M. Clinical review: severe malaria. Critical Care 2003; 7(4): 315-323.
2. International Center for Diarrheal Diseases and Research, Bangladesh. New strategies for treating falciparum malaria in Bangladesh. Health and Science Bulletin 2006; 4: 1-6.

3. Alam MS, Khan MGM, Chaudhury N, Deloer S, Nazib F, Bangali AM et al. Prevalence of anopheline species and their Plasmodium infection status in epidemic-prone border areas of Bangladesh. Malaria Journal 2010; 9: 2-8.

4. Stauffer W, Fischer PR.'Diagnosis and treatment of malaria in children. Clinical Infectious Diseases 2003; 37: 1340-1348.

5. Mockenhaupt FP, Ehrhardt S, Burkhardt J, Bosomtwe SY, Laryeas S, Anemana SD. Manifestation and outcome of severe malaria in children in Northern Ghana. The American Journal of Tropical Medicine and Hygiene 2004; 1(2): 167-172.

6. Moody A. Rapid diagnostic tests for malaria parasites. Clinical Microbiology Reviews 2002; 15: 66-78.

7. Iqbal J, Khalid N, Hira PR. Comparison of two commercial assays with expert microscopy for confirmation of symptomatically diagnosed malaria. Journal of Clinical Microbiology 2002; 40(12): 4675-4678.

8. Mankhambo L, Kanjala M, Rudman S, Lema VM, Rogerson SJ. Evaluation of the optimal rapid antigen test and species-specific PCR to detect placental plasmodium falciparum infection at delivery. Journal of Clinical Microbiology 2002; 40: 155-158.

9. Joshi HH. Monoclonal antibody based ELISA: an effective diagnostic tool for the diagnosis of falciparum malaria. Journal of Nepal Medical Association 2005; 44: 79-83.

10. Khan SA, Anwar M, Hussain S, Qureshi AH, Ahmad M, Afzal S. Comparison of optimal malarial test with light microscopy for the diagnosis of malaria. Journal of Pakistan Medical Association 2004; 54: 404-408.

11. Pattanasin S, Proux S, Chompasuk D, Luwiradaj K, Jacquier P, Looareesuwan S. Evaluation of a new plasmodium lactate dehydrogenase assay for the detection of malaria. Transaction of the Royal Society of Tropical Medicine and Hygiene 2003; 97: 672-674.

12. Cooke AH, Doherty T, Chiodini PL, Moody AH, Ries J, Pinder M. Comparison of a parasite lactate dehydrogenase based immunochromatographic antigen detection assay with microscopy for the detection of malaria parasite in human blood samples. Am. J. Trop. Med. 1999; 60 (2): 173-176.

13. Kakkilaya BS. Rapid diagnosis of malaria. Laboratory medicine 2003; 34(8): 602-608. 